УДК 339.138

\title{
МОДЕЛИРОВАНИЕ БИЗНЕС-ПРОЦЕССА УПРАВЛЕНИЯ МАРКЕТИНГОВЫМИ РИСКАМИ
}

\section{(C) 2013 г. О. А. Чурзина}

\section{ООО «Селлобай», г. Москва}

В статье, в соответствии с разработанными ранее подходами к управлению маркетинговым риском, рассматривается моделирование бизнес-проиесса управления маркетинговыми рисками в стандарте IDEF.

Ключевые слова: маркетинговый риск; стандарт IDEF; моделирование бизнес-проиес$c a$.

In the article author examines the modeling of marketing risk management business processes, using the IDEF standard. The examination is based on the previously developed approaches to marketing risk management.

Key words: marketing risks; IDEF standard; business process modeling.

Моделирование отдельных бизнес-процессов компании способствует повышению управляемости отдельными структурами компании и оптимизирует работу отдельных структур, более того - четко разграничивает функционал сотрудников компании и определяет области их ответственности.

Функциональное моделирование на основе стандарта IDEF, в основе которого лежит методология SADT, позволяет описать текущие процессы с точки зрения «как есть» и «как должно быть» [4]. В данной работе ограничимся использованием данного стандарта для моделирования только бизнес-процесса управления маркетинговыми рисками.

Моделирование на основе стандарта IDEF имеет ряд преимуществ:

- детальность описания процесса;

- комплексность;

- простота подхода;

- соответствие ISO 9000.

К недостаткам данного стандарта можно отнести:

- сложность понимания за счет большого количества уровней;

- сложность соединения нескольких процессов.

В качестве методологической основы моделирования бизнес-процесса управления маркетинговыми рисками принята методология управления рисками промышленных предприятий, представленная в работе [1]. Опишем процесс управления маркетинговыми рисками на основе разработанной модели, представленной на рис. 1 .

Целью данного моделирования является подготовить рабочую модель для внедрения управления маркетинговыми рисками на предприятии. В данной работе будет использовано программное обеспечение Bpwin 7.

В модели используются следующие функциии:

a) Управление маркетинговыми рисками - $\mathrm{A} 0$;

б) Классификация рисков - A1:

- выделить основные и вспомогательные бизнес-процессы маркетинга - A1.1;

- выделить область и среду управления - А1.2;

- спроецировать бизнес-процессы на область и среду управления - A1.3;

- сгруппировать маркетинговые риски - A1.4;

в) Оценка риска - A2:

- качественная оценка маркетинговых рисков - А2.1;

- количественная оценка маркетинговых рисков - А2.2; 


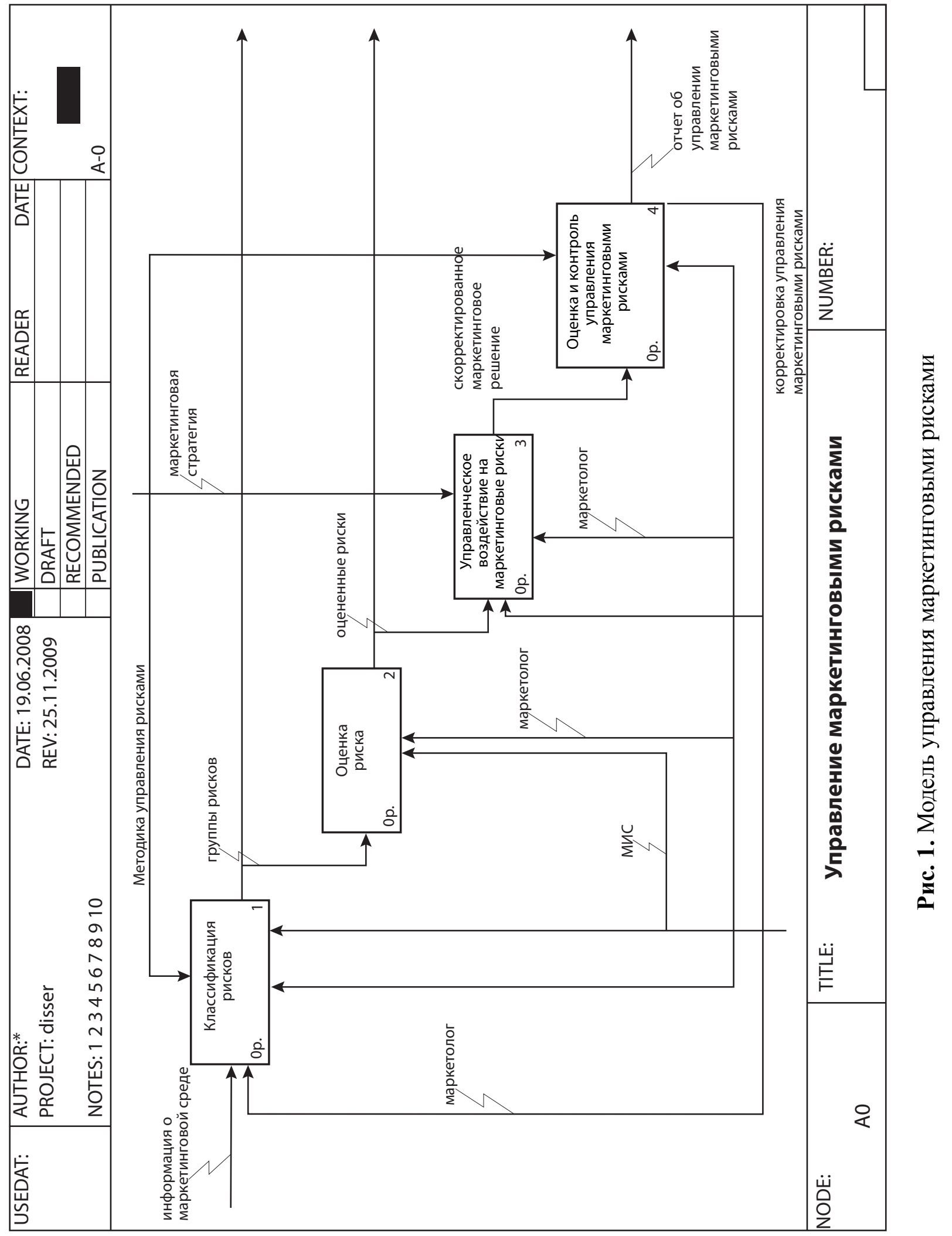


г) Управленческое воздействие на маркетинговые риски - А3:

- выбор метода воздействия на маркетинговые риски - A3.1;

- формирование программы управления маркетинговыми рисками - A3.2;

д) Оценка и контроль управления маркетинговыми рисками - A4:

- оценка информационного обеспечения УМР - А4.1;

- оценка действий менеджмента по УМР - A4.2;

- оценка методики УМР - A4.3.

В модели используются следующие определения:

Потребность в управлении маркетинговыми рисками - обоснованная потребность в управление маркетинговыми рисками.

Информация о внешней среде - данные о внешней среде функционирования предприятия.

Методика управления маркетинговыми рисками - методика, на основании которой происходит управление рисками

Маркетинговая стратегия - совокупность целевых ориентиров, определяющих деятельность компании в области маркетинга в долгосрочном периоде.

Маркетолог - специалист отдела маркетинга, функционал которого связан с оценкой и мониторингом рисков в области маркетинга.

Маркетинговая информационная система - информационная система управления маркетинга, является частью всей информационной системы предприятия.

Группы рисков - маркетинговые риски, классифицированные по определенным признакам.

Оценка риска — процесс расчета величины риска.

Управленческое воздействие на риск процесс влияния на существующие риски в целях их снижения или устранения.

Маркетинговое решение - план действий в области маркетинга.

Отчет об УМР - периодический отчет в установленной форме по работе системы управления рисками в области маркетинга.

Описание функииональньх блоков:

A1.1. Классификация маркетинговых рисков. На данном этапе определяются марке- тинговые риски, связанны с деятельностью конкретного предприятия.

1. Определить основные компоненты маркетинговой деятельности;

2. Процесс управления маркетингом представляется в виде основных и вспомогательных процессов;

3. Определить частные риски за счет проекции бизнес-процессов на область и среду управления.

А2.1. Оценка риска. В данном блоке на основании полученной классификации с учетом общей методики УМР происходит расчет величины риска по каждой группе.

1. Оценка риска происходит на основании качественных методик оценки, используя имеющуюся статистическую информацию в МИС. Определяется вероятность наступления риска;

2. Оценка риска происходит на основании количественных методик оценки, используя имеющуюся статистическую информацию в МИС. Определяется отклонение финансовых результатов маркетинговых мероприятий.

A3.1. Управленческое воздействие на маркетинговые риски. В данном блоке проводятся мероприятия по корректировки оцененных MP.

1. Определяются классификационные характеристики рассматриваемых рисков;

2. Определяются группы методов воздействия на маркетинговые риски;

3. Выбирается метод воздействия на маркетинговые риски.

A4. Оценка и контроль управления маркетинговыми рисками. В блоке проводится оценка системы управления маркетинговыми рисками.

1. Оценка информационного обеспечения УМР. Оценка уровня информационной обеспеченности процесса управления риском;

2. Оценка действий менеджмента по УMP;

3. Оценка методики УМР Оценка адекватности существующей технологии УМР текущей деятельности предприятия.

Таким образом, модель бизнес-процесса позволяет оптимизировать управление маркетинговыми рисками и документооборот, связанный с риск-менеджментом. 


\section{Литература}

1. Бадалова А. Г. Управление рисками производственных систем: теория, методология, механизмы реализации. Монография. - М.: ИЦ МГТУ «Станкин», «Янус-К», 2006. - $328 \mathrm{c}$.

2. Дойля П. Маркетинг, ориентиро- ванный на стоимость. - СПб.: «Питер», 2001. - $480 \mathrm{c}$.

3. Степанова E. A. Проектно-ориентированный подход к бизнес-процессам: Дисс. ... канд. экон. Наук. - М., 2005.

4. Черемных С. В., Семенов И. О., Ручкин В. С. Структурный анализ систем: IDEFтехнологии. Уч. пособие. - М.: «Финансы и статистика», 2003. - 208 с.

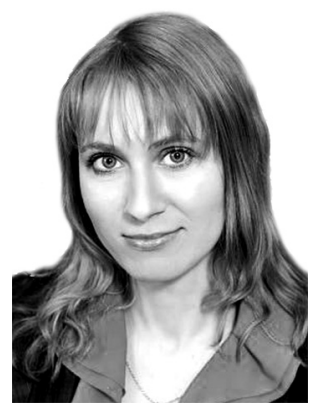

Ольга Аркадьевна Чурзина - директор по продажам ООО «Селлобай», аспирант Московского авиационного института (национального исследовательского университета).

Olga Arkadyevna Churzina - sales director at the «Sellobuy» public corporation, postgraduate student at the Moscow Aviation Institute (National Research University).

125993, г. Москва, А-80, ГСП-3, Волоколамское ш., д. 4 4 Volokolamskoye sh., A-80, GSP-3, 125993, Moscow, Russia Тел.: +7 (916) 715-85-13; e-mail: oltc@yandex.ru 